\title{
MULTICULTURALISMO, IDENTIDADES DISCURSIVAS E ESPAÇO PÚBLICO
}

\section{INTRODUÇÃO}

Em sua crítica aos antropólogos estruturalistas e cognitivistas que procuraram enfrentar a questão da diversidade das culturas reintroduzindo a Razão como fundamento universal da condição humana, Clifford Geertz (2000), em um ensaio provocativo e bem-humorado, defende o ethos do relativismo cultural como condição epistêmica necessária à vocação da Antropologia como pensamento crítico e de vanguarda. Para Geertz, foi através da ideia, certamente vaga e mal definida, de relativismo que a Antropologia mais perturbou a paz intelectual geral ao descentralizar as perspectivas do pensamento europeu demonstrando, por exemplo, que a ordem política e legal é possível, ainda que na ausência de um poder centralizado ou regras codificadas. Ao coletar inúmeros fatos aparentemente bizarros em terras e épocas distantes - o sacrifício humano dos astecas, a caça das cabeças dos jívaros etc. - a Antropologia, mesmo quando não pretendeu ser relativista tal como o evolucionismo ou difusionismo teria despertado o mundo europeu e o norte-americano para a tolerância uma vez que, se pessoas em outros lugares veem as coisas de modo diferente e as fazem de modo diverso, a "confiança em nossas próprias opiniões e atitudes e nossa determinação de fazer os outros partilhá-las tem uma base muito precária" (Geertz, 2000: 48).

O estilo provocador adotado por Geertz expressa, não resta dúvida, o grau de radicalização da polêmica que, no campo acadêmico anglo-americano, separa os defensores do paradigma positivista e determinista da teoria social - o qual postula uma descontinuidade entre o mundo objetivo e suas representações descritivas ao restaurar, por exemplo, conceitos biologizantes, como o de "natureza humana" -, e os detratores desse paradigma realista - os construtivistas de todos os horizontes, críticos de uma noção de "realidade" dotada de uma existência independente dos atores que a criam, das teorias que a descrevem e da linguagem que as materializa. "Sugerir que talvez não existam fundamentos 'sólidos' para os juízos cognitivos, estéticos ou morais”, instiga 
Geertz, "é ver-se acusado de descrer na existência do mundo físico, [...] de ver Hitler apenas como um sujeito de gostos pouco convencionais" (Geertz, 2000: 48). Para além da politização do debate que acusa os defensores do relativismo de nihilistas e promotores da anomia social, é interessante notar que Geertz, ao atribuir à Antropologia a tarefa crítica de "inquietar", trata o relativismo (e o antirrelativismo) como uma resposta genérica ao efeito do conhecimento de coisas distantes sobre nosso modo de ver as coisas (Geertz, 2000: 50). Ora, paradoxalmente, no momento mesmo em que o relativismo se impõe como uma posição antifuncionalista (que abandona a busca das essências) e antirracionalista (que defende a dimensão contextual e histórica de ver o mundo), as condições materiais de sua sustentação como ethos disciplinar se fragilizam. Esta perda de credibilidade está relacionada, por um lado, ao fato de que as práticas que "inquietam" não são mais "coisas distantes": as migrações, os meios de comunicação e de transporte, as exigências do mercado mundial há muito encolheram o mundo. Trata-se agora de conviver com várias espécies de "sacrifício humano", não mais como observador externo disposto à empatia, mas sim como práticas discrepantes (e irreconciliáveis) que coexistem em um mesmo quadro legal, seja ele nacional ou mundial. Por outro, à constatação de que o conceito antropológico chave definidor e organizador das diferenças - o conceito de cultura - perde, no mesmo processo, sua potência analítica. Em trabalho anterior (Montero et al., 2011) observamos que, enquanto a crítica desconstrucionista, pós-moderna e/ou pós-colonial, diluía o conceito de cultura na noção de texto, de dialogia, ou até mesmo na imagem literária de fiction, repensando o plano do simbólico em termos de negociação contextual das significações, a ideia essencialista de cultura é apropriada pelo campo político, tornando-se, ao mesmo tempo, um instrumento de autoafirmação identitária e uma linguagem jurídica de atribuição de direitos. Nesse processo a "etnicidade" deixa de ser compreendida por algumas correntes da teoria social como um atributo a priori de um grupo para se tornar um artefato produzido no campo discursivo e da prática social.

Com a emergência do conflito social definido em termos étnicos nas grandes cidades europeias e americanas, o relativismo perde seu fundamento ético e epistêmico, cedendo lugar para o problema da coexistência das diferenças em um mesmo espaço político nacional, problema este que os movimentos políticos e literários alcunharam de "multiculturalismo". Como no caso do conceito de "relativismo", o termo abriga um leque quase infinito de posições teóricas e políticas. O que há em comum entre elas, a nosso ver, é a percepção de que a questão da "diferença" passa a exigir novas modalidades de gerenciamento e de partilha do espaço político. Pode-se talvez compreender, como sugere Semprini (1999), as reivindicações multiculturais como um sintoma das grandes mutações em curso nas sociedades pós-nacionais que se veem obrigadas a redefinir o lugar das diferenças no interior de seu sistema 
social. Propomo-nos, neste ensaio, a contribuir para o avanço desta reflexão desenvolvendo dois principais argumentos:

a) Por um lado, tomando como referência um caso de reivindicação de direitos étnicos no Brasil, identificar a dinâmica desses novos processos jurídico-políticos de "respeito às identidades", em particular, ressaltar o fato de que as identidades são construídas discursivamente e dependem de um trabalho de mediação cultural.

b) De outro, caracterizar a especificidade do multiculturalismo em contraposição ao relativismo cultural e demonstrar como os modelos de integração que ele propõe dependem das particularidades históricas dos Estados nacionais e de sua contrapartida, as configurações particulares do espaço público. Tomaremos como referência para essa reflexão o debate, no Brasil, em torno das "etnias".

\section{ETNIA E RAÇA: A INVENÇÃO SOCIAL E POLÍTICA DAS IDENTIDADES}

Em seu trabalho de 2005, Mocambo, José Maurício Arruti procura descrever o processo social de metamorfose e divisão de uma mesma comunidade rural no Sergipe, Nordeste do Brasil, na década de 1990, em dois grupos identitários distintos: uma parte da comunidade se transformou nos índios Xocós; a outra parte se assumiu como descendentes de negros quilombolas (escravos rebeldes fugidos das fazendas) e tomou o nome de Mocambo. Chamam a atenção, neste caso, algumas idiossincrasias importantes que por si só elucidam os paradoxos inerentes às reivindicações multiculturais do tempo presente: em primeiro lugar, a comunidade que assim se dividiu etnicamente entre negros e índios mantivera durante décadas, e mantém até hoje, estreitas relações de parentesco e cooperação; em segundo lugar, aqueles que foram reconhecidos como índios Xocó não eram portadores dos sinais distintivos que ordinariamente são mobilizados para caracterizar esse tipo de etnicidade: muitos tinham a pela negra ou olhos claros, falavam apenas português, eram católicos e viviam de maneira indistinta com relação a outras comunidades rurais da região. Ao longo das gerações sobreviveram da lida com o gado, como meeiros nas plantações de arroz e algodão, e habitaram pequenas vilas de 50 a 60 habitantes, respeitando os dias santos e organizando procissões marcadas por cantos e rezas para o padroeiro da comunidade. No centro do vilarejo a igreja católica, inspirada nos padrões arquitetônicos das igrejas rurais medievais portuguesas que, no caso dos Xocó, é uma construção dos missionários capuchinhos datada do século XVII; finalmente, parte significativa da população de Mocambo se opôs ao processo de reconhecimento do grupo como remanescentes de quilombo, preferindo preservar o status quo de camponeses, no que foram apoiados por alguns grupos Xocó. 
Arruti (2005) e French (2009) examinam o complexo processo social e político que diferenciou etnicamente os Xocó dos Mocambo, embora tenham permanecido muito semelhantes em todos os aspectos relativos ao seu modo de vida. Os Xocó foram se tornando índios ao serem colocados, nos anos 1980, sob o guarda-chuva institucional da Fundação Nacional do Índio (Funai) responsável oficial pelos direitos e proteção dos territórios indígenas; os Mocambo foram reconhecidos, anos mais tarde, descendentes de escravos sob o guarda-chuva institucional do Instituto Nacional de Colonização e Reforma Agrária (INCRA).

Segundo French (2009), a conjuntura política explosiva da luta pela terra entre fazendeiros politicamente poderosos e camponeses pobres no Nordeste brasileiro nos anos 1980 teria levado um grupo de meeiros à ação extrema de se declararem índios; "escolha" esta que tinha como uma de suas implicações abdicar de uma cidadania "plena" enquanto brasileiros e assumir o estatuto legal de "tutelados". A "escolha" acabou sendo bem-sucedida e o reconhecimento da reserva indígena Xocó foi decretada em 1991. Mas o conflito de terras permanecia agudo para seus vizinhos e parentes que naqueles 20 anos não haviam aderido ao pleito de indianidade. Nos anos seguintes uma nova alternativa começou a desenhar-se. Ao lado das cláusulas de proteção das populações indígenas, a nova Constituição de 1988 havia editado uma outra, que dava aos sobreviventes de antigos quilombos a titularidade da terra que estivessem ocupando. Embora, como no caso dos que se tornaram Xocós, esse grupo de residentes nada soubesse a respeito de uma história construída sob o imperativo de requerimentos legais para o reconhecimento de um quilombo, logo perceberam que ali havia um caminho para conquistar a posse da pequena parcela de terra de Mocambo. Neste caso, o sucesso do pleito do reconhecimento da identidade quilombola, iniciado em 1993 e conquistado em 2000, foi o resultado da experiência bem-sucedida dos Xocós em conquistar uma identidade indígena, por um lado, e a percepção de que se eles não pleiteassem seu direito àquela parcela de terra os próprios Xocós o fariam, por outro; além disso, foi fundamental o apoio ativo de agentes da Comissão Pastoral da Terra (CPT), ligada à Igreja Católica e imbuída dos pleitos da Reforma Agrária, da Associação Brasileira de Antropologia, cujo grupo de trabalho endossou uma definição mais ampla de "remanescentes de quilombos" de modo a fazê-la coincidir com as reivindicações dos movimentos negros, e de alguns advogados dispostos a reconstruir a disputa nos termos legais adequados para torná-la uma causa quilombola. ${ }^{2}$

As tramas e conflitos do processo de produção simbólico, político e legal das identidades indígenas e negras dessa população, com suas alianças e confrontos, é demasiadamente complexa e cheia de detalhes para que possamos resumi-la neste ensaio. Recomendamos uma leitura exaustiva dos excelentes trabalhos de French e Arruti citados anteriormente. No que diz respeito ao que 
podemos fazer neste artigo, tomaremos esses casos como referência para colocarmos algumas questões-chave no que diz respeito às demandas de identidade étnica na cena contemporânea, a saber: em quais condições uma narrativa de etnicidade se torna plausível?

O relato desta conquista de direitos territoriais na base de reivindicações étnicas mostra claramente como, pelo menos nestes casos, a etnicidade é uma categoria construída para fins de obtenção de direitos específicos. French (2006: 99) observa com acuidade que, tanto no caso da identidade Xocó, como no caso do quilombo Mocambo, a natureza construída das identidades não impediu o governo de reconhecer e garantir o direito à propriedade da terra, para essas comunidades. Como se pode explicar esse fenômeno?

Diversos estudos sublinham o fato de que a questão da autoidentificação étnica é sempre o resultado de uma luta política por direitos, e a definição dos prerrequisitos que darão razoabilidade aos pleitos (provas históricas, por exemplo, da escravidão e fuga no século XIX, registros de continuidade na ocupação de determinado território etc.) se constrói na linguagem do direito e na lógica de sua argumentação. Essa "juridificação" do processo de produção de identidades - dinâmica discursiva que se apropria da gramática do campo do direito para produzir a legalização dos grupos étnicos - retira, evidentemente, o fenômeno das identidades do campo da cultura (enquanto emanação do modo ser de um grupo) e o projeta no campo da política. Por essa razão, o que aos olhos do senso comum poderia parecer um escândalo moral ou uma fraude - a produção social e simbólica das identidades para finalidades políticas - é percebido pelos agentes envolvidos como um modo negociado de lançar mão das leis existentes para promover uma justiça redistributiva não mais apoiada no paradigma da desigualdade de classes. French propõe o conceito de "legalização da identidade" como modelo analítico para a compreensão desses processos nos quais as instituições legais e políticas de uma nação interagem com elementos de identidades locais, transformando-as e dando-lhes visibilidade.

Tal como French, José Maurício Arruti também está interessado na compreensão dos processos de "juridificação" das identidades. No entanto, seu enfoque dá mais importância aos processos performáticos de produção da autenticidade identitária. Inspirado no paradigma da "política do reconhecimento" de Charles Taylor (1994), ${ }^{3}$ Arruti trata o caso do quilombo Mocambo como um fenômeno de mobilização da imagem de um grupo de modo a torná-lo visível na esfera pública para que conflitos locais reverberem na esfera do direito (2005: 44).

Qualquer que seja o partido teórico adotado para examinar os processos de "juridificação" das identidades, emerge como questão aparentemente paradoxal o fato, já mencionado no início, de que, enquanto a teoria antropológica se move na direção do entendimento desses processos no plano discursivo, os 
processos de "juridificação" estimulam mediadores a "resgatar" uma identidade profunda e autêntica, anterior à política e às negociações. Relatos históricos e originários têm mais força simbólica para conferir legitimidade no plano prático-político aos pleitos étnicos.

Muitos autores já chamaram a atenção para esse fenômeno no qual a reflexão acadêmica e a ação política parecem andar em sentidos contrários. ${ }^{4}$ Segundo Manuela Carneiro da Cunha, esse desencontro entre teoria e prática suscita um problema antropológico instigante: compreender os processos, as questões e as transformações implicadas no ajuste e na tradução da categoria analítica de cultura em instrumento político (2009: 313). Uma das maneiras de fazer avançar o entendimento desse tipo de "tradução", sugere a autora, seria desenhar um mapa contextual suficientemente amplo que fosse capaz de incluir na mesma análise escalas de diferente dimensão tais como: emergência de novos instrumentos legais internacionais; decodificação de interesses locais, nacionais e mundiais etc. Outro posicionamento teórico fundamental para enfrentar esse tipo de questão antropológica é assumir que identidades, hibridismos, sincretismos etc., não são emanações do modo de ser de um grupo particular, tampouco o resultado imediato de suas condições de vida. A perspectiva histórica torna-se aqui fundamental como instrumento analítico de objetivação desses processos. As identidades étnicas são tomadas como fenômenos históricos que podem ser compreendidos quando se põe sob a lente do observador "o que fazem", material e simbolicamente, os vários agentes em interação: além dos "nativos", os advogados, antropólogos, agentes do governo etc. Este é o modelo analítico da mediação cujo detalhamento sugeri em trabalho anterior (Montero, 2006).

Transparece claramente na narrativa de Arruti a importância do trabalho de mediação no complexo processo de categorização das identidades. Padres católicos e antropólogos coligiram memórias, organizaram relatos, produziram provas e convenceram os "nativos" da necessidade de se autoidentificarem, e advogados colaboraram na formatação da causa jurídica percebendo a oportunidade que a Constituição oferecia de deslocar o pleito do campo do reconhecimento da posse (direito dos "posseiros") para o reconhecimento da tradição. A recorrência desses processos de mediação simbólica e prática nos levou a construir uma abordagem que deslocasse o interesse clássico do olhar antropológico pela reconstituição das culturas e cosmologias "tal como elas são", para o exame dos agentes mediadores e dos processos de produção das diferenças étnicas, hibridismos e identidades. Isto porque, como já bem demonstraram os estudos pós-coloniais, o local e o global se articulam de tal modo que frustram qualquer tentativa analítica de "retorno" a histórias originais fechadas e centradas em termos étnicos. É o trabalho simbólico e prático dos agentes mediadores que tornam convincentes e plausíveis as construções identitárias.

Quem são esses agentes, qual seu repertório, quais articulações se tornam plausíveis e por que, são algumas das novas questões que alimentam a nossa reflexão antropológica sobre esses fenômenos. Assim, o que passa a nos interessar nesta nova abordagem é o escrutínio dos processos de mediação não tanto no sentido que a Sociologia deu ao termo, sublinhando a capacidade de certos agentes em intermediar interesses dos grupos que representam junto ao Estado, mas, sobretudo, buscando compreender o campo das relações simultaneamente prático-discursivas no qual, por meio de com- 
parações, traduções, reconstituições históricas, codifica-se uma forma particular de pertencimento. O modelo analítico da mediação se propõe a jogar luz na dinâmica discursiva das agências e no modo como constroem e tornam verossímeis essas categorias sociais de autodefinição.

Já no modelo processual proposto por Arruti (2005: 45) para o estudo desse tipo de situação seria possível identificar nessas ações quatro momentos distintos:

a) Em um primeiro momento está o processo de "nominação" - ele diz respeito à "escolha" da categoria jurídica que será acionada (quilombola, posseiro, índio, imigrante, populações tradicionais etc.) de modo a instituir um certo grupo como sujeito de direitos e deveres e como objeto de ação do Estado;

b) Em um segundo momento se desenvolve o processo de "identificação", isto é, reunião de documentos, informações, relatos e testemunhos de comprovação das identidades e qualificação das formas de desrespeito acumuladas;

c) Com o acúmulo de "fatos" e "provas" se abre passagem para o processo de "reconhecimento", a passagem para o debate na esfera pública e o desenvolvimento da controvérsia em torno da legitimidade e verossimilhança do pleito;

d) $\mathrm{Na}$ fase final, se o desfecho da controvérsia leva a opinião pública a reconhecer o fundamento do que é reivindicado, chega-se à esfera da normatividade e à regulamentação de um determinado tipo de direito no plano jurídico que, no exemplo aqui mencionado, é a propriedade da terra.

Até o momento, nos ocupamos em demonstrar como diferentes modelos teóricos procuraram dar conta do fenômeno aparentemente paradoxal no qual os processos de representação das identidades no espaço público, embora se apoiem na ficção da autenticidade da cultura, constituem-se como verdade no âmbito mesmo das interações e do jogo político.

Mas se nos colocarmos a questão do ponto de vista do Estado, devemos nos perguntar como esses processos de autoconstituição de identidades afetam o modelo de coesão nacional clássico, baseado no caso brasileiro, no imaginário da mestiçagem e da assimilação. Não é mais novidade afirmar que as mudanças nos contextos ideológico e jurídico global, no qual causas ligadas à questão ambiental e à questão dos direitos humanos, por um lado, e a diversificação da base étnica das sociedades, por outro, interpelaram a noção de soberania popular associada à construção dos Estados nacionais. Nesse sentido, o modelo clássico de integração em bases nacionais homogêneas se fragiliza como ideologia política e precisa ser ressignificado. Passemos então à análise do modo com o multiculturalismo foi incorporado à agenda política nacional e dos novos dilemas políticos e teóricos que suscitou. 


\section{MULTICULTURALISMO E ESTADOS NACIONAIS}

Nos últimos vinte anos tem se consolidado um crescente consenso público internacional de que o reconhecimento dos direitos das minorias não é uma questão arbitrária ou instrumental, mas ao contrário, assunto que diz respeito aos direitos fundamentais (Arruti, 2005: 43). Em sua leitura política do multiculturalismo, Will Kymlicka (2001) observa que essa inflexão estimula a pressão para a internacionalização desse tipo de direito, tornando as questões étnicas e de minorias uma matéria de regulação e até mesmo de intervenção internacional.

Nesse novo contexto mundial se coloca como questão central a matriz de integração social em torno da qual se dará a reacomodação das diferenças. Dissemos acima que a migração intensiva e os meios de comunicação aproximaram as diferenças culturais de um modo tal que elas passam a ter que negociar os termos de sua convivência dentro de um mesmo marco legal, ou promover a "solidariedade entre estranhos", na expressão de Brunkhorst (Costa, 2009). É claro que, os diferentes processos históricos de formação dos Estados nacionais modificam os termos a partir dos quais esse tipo de negociação é formulado. Will Kymlicka, por exemplo, tomando como referência a formação do Estado nacional canadense, sugere a existência de dois tipos distintos de minorias étnicas: as "nações minoritárias" (povos preexistentes à instituição do Estado nacional, com história própria de autogoverno e uma cultura e língua comuns) e os "grupos poliétnicos" (imigrantes que integraram voluntariamente um Estado nacional existente e que, portanto, deveriam integrar-se nas normas da nação de acolhimento).

No caso brasileiro, o processo de constituição de uma nacionalidade que se inicia com a Proclamação da República, em 1889, enfrentou o problema de construir os requisitos da soberania popular a partir de uma matéria-prima bastante heterogênea: negros africanos recém-saídos da escravidão, mestiços livres, populações indígenas em diferentes momentos de convivência com o mundo não-indígena, imigrantes europeus pobres, quadros da burocracia estatal de ascendência portuguesa etc. Intelectuais e governantes se dedicaram a equacionar esse dilema da nacionalidade ao longo de quase todo o século XX. A literatura a esse respeito é bastante vasta: ${ }^{5}$ o "povo brasileiro" foi o objeto mais recorrente de todas as disciplinas acadêmicas, da Sociologia à Ciência Política, desde 1930, quando são fundadas as primeiras universidades em São Paulo e no Rio de Janeiro. ${ }^{6}$ O modelo jurídico de incorporação das populações indígenas e seus territórios ao processo de construção da nação foi o da tutela, que perdurou pelo menos até a Constituição de $1988 .{ }^{7}$ No caso dos negros, a "raça" foi transformada em herança cultural africana a partir da obra inaugural de Gilberto Freyre, que fez da miscigenação a grande virtude da nação brasileira. Desse modo, o modelo de constituição da soberania foi, no caso do 
Brasil, calcado em uma política de integração e assimilação das diferenças de cor na forma de uma cidadania miscigenada abstrata, indiferente às particularidades. É preciso lembrar também que, ao longo de todo o período imperial (1822-1888) o Estado envidou uma política de conservação da unidade territorial da ex-colônia através da manutenção do português como língua nacional e da repressão policial a toda forma de tentativa separatista, que não foram poucas. Nenhuma das Constituições brasileiras admitiu uma identificação individual em termos étnicos ou raciais. O registro geral do cidadão em nenhum momento incorporou alguma informação a respeito de cor de pele ou pertencimento étnico.

O contexto político mundial dos anos 1990, no entanto, começa a cristalizar-se em torno de um entendimento jurídico de discriminação positiva das diferenças que passa a promover políticas antiassimilacionistas. A Conferência da Organização Internacional do Trabalho de 1989 talvez seja um marco importante nessa direção. Com a participação de inúmeros representantes de organizações indígenas, aprovou o Convênio 169 sobre Povos Indígenas e Tribais que em seu artigo $1^{\circ}$ adota o termo "povos" no lugar de populações indígenas - de modo a designar uma forma de pertencimento subnacional -, e seu artigo $7^{\circ}$ afirma o direito dessas comunidades de decidirem suas próprias prioridades em relação ao desenvolvimento quando este afete suas vidas, crenças, instituições, bem-estar espiritual e as terras que ocupam ou utilizam de alguma maneira. Rinaldo Arruda (2005: 87-100) observa que, de um modo geral, o Convênio propõe que esses povos assumam o controle de suas próprias instituições e formas de vida, de seu sistema de educação e suas formas de desenvolvimento, de maneira a manter suas identidades e resistir aos modos de integração assimilacionistas implícitos nas normas anteriores. Ao lado disso, o documento também prevê obrigações para os Estados que vão no sentido de propor medidas para salvaguardar as culturas e o meio ambiente desses povos. As preocupações embutidas nesta revisão das normas internacionais sobre os povos indígenas foram, em parte, absorvidas pela revisão constitucional brasileira de 1988, que reconheceu "aos índios sua organização social, costume, línguas, crenças e tradições e os direitos originários sobre as terras que tradicionalmente ocupam, competindo à União demarcá-las proteger e fazer respeitar todos os seus bens". Nesse sentido, o Estado brasileiro, que até muito recentemente estava embebido na ideologia nacional do "mulatismo" como modelo de coesão social, isto é, o sincretismo das três "raças" formadoras da nação - negros, brancos e índios - passa a assumir-se como formado por heranças paralelas e pluriétnicas. O pluralismo significa aqui o reconhecimento do direito à diferença cultural e estipula alguns direitos coletivos tais como o direito ao território tradicional, à sociodiversidade, ao meio ambiente e à biodiversidade (Arruda, 2005: 100).

Nessa formulação, a palavra pluri(étnica) é apenas descritiva, e remete ao pluralismo como doutrina política. Nesse sentido, promove-se uma aposição 
da ideia liberal de liberdade - a convivência pacífica e respeitosa de pensamentos diferentes - com a ideia de convivência entre culturas que vivem de maneiras diferentes. Mas podemos nos perguntar em que medida o pluralismo étnico, assumido em parte pela legislação brasileira, se confunde com o multiculturalismo tal como ele está posto no debate internacional. Segundo Giovanni Sartori, quando o multiculturalismo é compreendido como a descrição de uma situação de fato, na qual uma multiplicidade de culturas convive no mesmo espaço social, ele não colocaria problemas para a concepção pluralista de mundo (2001: 65). Mas como doutrina política que defende a multiplicação sempre crescente das diferenças, pluralismo e multiculturalismo passam as ser noções antitéticas. Para este autor o pluralismo busca assegurar o nível de assimilação necessário para promover a integração, enquanto o multiculturalismo encontra virtudes políticas na própria produção das diferenças.

De um modo geral, sob o conceito de multiculturalismo subjazem diferentes ideias de qual seria o principal índice definidor de uma "identidade cultural": pode ser a língua, mas também o território, os costumes, a religião, os ritos etc. Na maior parte das vezes apenas um ou dois desses indexadores podem ser suficientes para determinar as fronteiras de um grupo e sua ancestralidade. No entanto, para que a cultura se traduza em instrumento político, esses marcadores não são suficientes. Na perspectiva multiculturalista de autores tais como Charles Taylor é preciso ainda que a ideia de que um grupo particular está sendo "oprimido" por não ser "reconhecido" como tal, esteja também presente. Quando um grupo reivindica uma identidade étnica isso significa, implicitamente, que sua cultura está em perigo de extinção. Levando-se em conta que a controvérsia em torno do multiculturalismo interpela de várias maneiras o pluralismo, voltemos ao caso brasileiro, de modo a compreender como algumas das "soluções políticas" propostas no bojo do novo paradigma filosófico-político do pluralismo étnico enfrentaram, na prática, o dilema colocado pelo multiculturalismo que opõe a defesa da igualdade social à defesa da desigualdade étnica e de direitos.

Por razões demasiado complexas para que pudessem ser aqui enumeradas, é certo que o modelo histórico anterior de coesão social, baseado na assimilação das diferenças em nome da aculturação e da civilização, perdeu credibilidade como utopia política. Por um lado, as ideias de "civilização" e "progresso" como "formas desejáveis de convívio social" sofreram desgaste crescente na medida em que revelam para as classes urbanas bem pensantes sua face de violência e destruição no processo de expansão colonialista do Estado nacional sobre os territórios habitados por populações indígenas ao longo do século XIX e, principalmente, na primeira metade do século XX. Por outro, com o fim do regime militar nos anos 1980, e o forte desejo de reconstrução das instituições democráticas da nação, o ideal republicano de igualdade civil começa a ser percebido como demasiadamente formal e cúmplice na perpetuação 
das desigualdades ao menosprezar as diferenças de raça, sexo e cultura como perpetuadores dos mecanismos de exclusão. Assim, a diferenciação, a reversão mesma do sincretismo começa por tornar-se um valor no panorama político brasileiro dos anos 1990. No empuxo dessa nova gramática, vimos acima como as categorias jurídicas de identificação acabaram por transformar coletividades camponesas e/ou sertanejas em grupos étnicos. A pergunta que devemos nos fazer então seria, no caso brasileiro, qual o modelo de pluralismo e de coesão social implícito nesse novo tipo de reconhecimento identitário de base étnica e com que argumentos ele constrói suas formas de plausibilidade?

Um dos aspectos mais interessantes do processo aqui relatado é o fato de que, pelo menos no caso brasileiro, a pressão das causas ambientais e conservacionistas foram, em grande parte, responsáveis pela construção das categorias de linguagem que deram visibilidade às reivindicações da diversidade cultural e étnica e que abriram o caminho jurídico para sua legitimação. É porque se estabeleceu a convicção de que as populações indígenas - e, por extensão do modelo, também as comunidades tradicionais - protegem as florestas onde seus territórios foram, em parte, reconhecidos e delimitados. Até muito recentemente as grandes linhas que caracterizavam as divisões no debate sobre os recursos territoriais nacionais colocavam em dois campos distintos os que defendiam a produção de alimentos com capital intensivo e a reserva de terras para a reforma agrária. ${ }^{8}$ O INCRA financiava fortemente projetos de alocação de pequenos proprietários rurais em áreas ainda não colonizadas da Amazônia. No entanto, a pressão internacional contra o desmatamento, a incorporação progressiva dessas pautas nas políticas públicas nacionais em função do aumento da percepção interna do crescimento da degradação das florestas pelo contrabando e pelas queimadas, obriga o aparato jurídico-político do Estado a mudar sua forma de definir o território nacional e suas finalidades coletivas.

A nosso ver, a passagem do reconhecimento étnico pelas pautas ambientais acabou por subsumir as potenciais demandas de autonomia territorial e política das populações indígenas ao consenso em torno dos interesses do Estado nacional, subtraindo a credibilidade das vozes que, inspirados nos movimentos indigenistas de outros países latino-americanos, como o da Bolívia de Evo Morales, ${ }^{9}$ consideravam legítimo o pleito da formação de nações separadas. O jurista e ex-presidente da Funai, por exemplo, ao responder a uma pergunta sobre a licitude de uma comunidade negar a existência do Estado como uma estrutura superior de poder, afirmou que essa recusa, embora não seja "lícita do ponto de vista da legislação brasileira, é legítima do ponto de vista do direito de um povo" (ISA, 2000: 92).

A novidade introduzida pelo modelo jurídico de reconhecimento das terras indígenas - as reservas - foi a de garantir a propriedade das terras nas mãos do Estado e colocar em termos de "coletivos indígenas" tanto o usufruto quanto a gestão ambiental desses imensos territórios. ${ }^{10}$ No desenho desse fi- 
gurino legal caberia ao Estado apenas fiscalizar se o uso dos recursos naturais pelas populações indígenas não estaria em desacordo com os interesses maiores da nação, quais sejam, o de proteção de seus recursos ambientais e a preservação da integridade do território ainda percebido como nacional.

Mas é claro que a tarefa tão complexa de gerenciar exigiu, como contrapartida, formas de mediação que tornassem possível, como não poderia deixar de ser, a construção de uma forma de representação política que, para além dos conflitos entre chefes locais, pudesse dialogar com as agencias governamentais. Quando foi presidente da Funai, Carlos Frederico Marés, para enfrentar o contínuo conflito dos índios Xavante entre si e deles com a Funai, propôs uma reorientação e redução das administrações regionais e a organização de Conselhos que passaram a ser responsáveis pela avaliação e a aprovação de projetos de desenvolvimento. As formas locais de organização política são assim remodeladas e reinventadas pela ação das agências mediadoras de modo a promover uma indexação das formas locais aos procedimentos de representação em funcionamento no espaço público político.

Outro exemplo significativo nessa direção, relatado por Manuela Carneiro da Cunha (2009), foi a criação, em 1990, da Reserva Extrativista do Alto Juruá que, tomando como modelo as reservas indígenas, transformou seringueiros em "populações tradicionais" responsáveis pela conservação das florestas. ${ }^{11} \mathrm{O}$ conflito naquela área de extração de borracha fora até então tratado como problema fundiário e sindical, e as primeiras iniciativas político-legais dos trabalhadores contra seus patrões foram direcionadas ao INCRA. A decretação das reservas extrativistas como áreas de proteção ambiental foi, segundo a autora, uma escolha tática: "os seringueiros não sabiam que estavam conservando, achavam que estavam produzindo borracha" (2009: 296). Mas o que nos parece mais interessante neste caso é observar que os programas de sustentabilidade e os projetos conservacionistas exigiram certa "adequação" das comunidades locais ao figurino. Assessores, antropólogos, agentes de várias ONGs, quadros governamentais, puseram-se em campo para angariar recursos, escrever projetos e obter a capacidade técnica para executá-los. Desse modo, o gerenciamento da área pela população local dependeu da articulação desses grupos a vários níveis da sociedade nacional e internacional - agências de fomento, universidades e o Instituto Brasileiro de Meio Ambiente e de Recursos Naturais (Ibama) ao qual estavam oficialmente subordinados. Além disso, levou ao aprendizado de diversas formas de autogoverno que articulou a autoridade dos velhos mateiros às formas de associações inspiradas no modelo da democracia representativa.

Apesar de a literatura internacional reconhecer que, nas condições contemporâneas, os apelos às identidades nacionais unitárias soem anacrônicos, os exemplos aqui mencionados lançam luz sobre as especificidades do caso brasileiro: apesar da renúncia ao modelo assimilacionista, a integração das 
diferenças em bases do Estado-nação não foi abandonada, mas ao contrário, reinventou-se a partir de um novo compromisso ideológico-político - o de garantir o desenvolvimento de maneira "sustentável". Como bem observa Marcos Nobre (2002: 22), o conceito de "desenvolvimento sustentável" realizou a façanha de reunir sob si visões completamente antagônicas: a agenda ambientalista que considera que é preciso frear o desenvolvimento porque os recursos da natureza são finitos, e as pautas desenvolvimentistas que defendem a necessidade do combate à pobreza via o crescimento econômico e o avanço tecnológico da sociedade. Ao tomar como categoria mediadora para a organização de alguns pleitos identitários a questão ambiental, o Estado foi capaz de produzir, nestes casos, um novo consenso: as formas de distribuição do território nacional devem garantir, ao mesmo tempo, a defesa das diferenças (embora fortemente amarradas ao marco legal da nação) e a aceitação dos parâmetros internacionais de modalidades não-predatórias de desenvolvimento econômico. No processo, novas formas de representação cultural e política das diferenças vão sendo elaboradas e performatizadas enquanto identidades étnicas no espaço público.

\section{CONSIDERAÇÕES FINAIS}

O diplomata e cientista político Sérgio Paulo Rouanet observa, com razão, que quase todos os intérpretes do Brasil tiveram uma atitude de indiferença com relação à democracia. Tanto a direita quanto a esquerda praticaram "uma aliança satânica" com a democracia, provoca ele. Nos argumentos usados por Sérgio Buarque de Holanda, por exemplo, a democracia seria algo inadequado ao Brasil porque importada e inautêntica, "sem raízes na realidade nacional". Já nas concepções do pensamento de esquerda a democracia foi desqualificada como mera fachada formal burguesa e instrumento de dominação de classe (2009: 27-29). Assim, durante décadas o pensamento social brasileiro pensou as questões pertinentes da constituição da identidade nacional sem que dela fizesse parte a edificação e o fortalecimento de instituições democráticas.

A novidade para a imaginação política brasileira reside no fato de que pela primeira vez o pensamento relativo às diferenças está associado ao problema da construção de instituições democráticas e não do Estado nacional. As disputas políticas recentes em torno da diversidade cultural e do respeito às diferenças têm, com efeito, como substrato, a defesa e robustecimento do estado democrático de direito. Por essa razão, no debate contemporâneo sobre a democracia os processos de construção de uma Esfera Pública Política tem ganhado um lugar central. Para autores como Sérgio Costa (1997), ${ }^{12}$ os meios de comunicação de massa, a organização da sociedade civil e os espaços comunicativos primários são os contextos a partir dos quais essa esfera se constrói 
historicamente. Qualquer que seja o modelo teórico de Esfera Pública adotado, estabeleceu-se certo consenso em torno da ideia de que, nos regimes democráticos, a ordem política deve ser fundada no consentimento e, consequentemente, as decisões políticas têm que ser permanentemente justificadas, pois dependem de algum tipo de anuência para adquirir validade. Esse fenômeno que se inicia, no caso da organização da esfera pública brasileira, nos anos 1970 com os movimentos sindicais e de classe, alcança, nos anos 1990, a esfera da cultura. A questão das identidades étnicas começa a se colocar mais agudamente como problema político quando está em jogo, a partir dos anos 1990, a implementação de um modelo de democracia participativa. A ideia de que a democracia liberal não fora capaz de superar as desigualdades sociais e defender os direitos dos mais pobres articulou-se à ideia de que a desigualdade tinha, em parte, fundamento no desconhecimento dos direitos das minorias. Esse deslocamento passou a exigir dos agentes uma nova forma de reflexividade sobre as diferenças culturais de modo a produzir argumentos e justificativas de pertencimento capazes de fundar legitimamente as identidades e seus pleitos.

A questão que nos colocamos, pois, neste texto, foi a de explicitarmos as condições particulares do campo político brasileiro de modo a compreendermos os mecanismos simbólicos e pragmáticos que justificaram o reconhecimento de algumas identidades étnicas específicas e lhe conferiram validade legal. O modo particular como desigualdades sociais e diferenças culturais se articularam nestes casos é bastante interessante.

A questão ambiental, formulada em termos de "desenvolvimento sustentável”, foi a estratégia discursiva que conseguiu legitimar o reconhecimento das diferenças étnicas no plano dos direitos. Esta articulação foi possível porque suas resultantes não ameaçavam dois dos princípios históricos fundamentais da soberania do Estado nacional brasileiro: a preservação da integridade territorial e a subordinação política das comunidades étnicas ao poder estatal. Assim, apesar do abandono do modelo ético da mestiçagem, a matriz da integração nacional em termos de território e aparato estatal foi, e continua sendo, a nosso ver, uma condição sine qua non e um limite claro no processo brasileiro de reconhecimento e acomodação dos pleitos de respeito às diferenças.

Entretanto, se as causas ambientais articularam com sucesso a proteção de direitos culturais à manutenção da soberania nacional via conquistas territoriais, isto não se deu exatamente porque havia "culturas em perigo", como sugere Taylor. Pelo menos nos casos aqui mencionados, como o das "populações tradicionais" ou dos "quilombolas", esse "perigo" dizia mais respeito a questões de desigualdades econômicas e igualdade de oportunidades do que de tradições a serem preservadas, já que estas não estavam presentes de antemão. Elas teriam como funcionalidade primeira criar instrumentos alternativos para que parte da população pudesse acessar o Estado.

Ainda assim, nos parece que a euforia bem intencionada de muitas das agências de mediação que usam estrategicamente a produção das diferenças 
para a conquista de direitos e correção das desigualdades deveria ser matizada pela percepção de duas dificuldades principais: de um lado, os grupos assim adstritos nem sempre estão interessados em comportar-se e apresentar-se segundo o figurino identitário que os constituiu; de outro, nos processos de reconhecimento dos pertencimentos o direito desempenha, como vimos, um papel fundamental na criação e na reificação das identidades étnicas. Deste modo, não se pode esquecer que, como bem observa Sérgio Costa (2006: 29), a construção de identidades coletivas acaba sempre levando a algum tipo de essencialização e, por via de consequência, engendrando novos mecanismos de exclusão.

Recebido para publicação em fevereiro de 2011.

Paula Montero é doutora em Antropologia pela Universidade de São Paulo (USP), professora titular do Programa de Pós-Graduação em Antropologia Social da mesma instituição e presidente do Centro Brasileiro de Análise e Planejamento (Cebrap). Sua área de interesse é Antropologia Urbana, com ênfase nos seguintes temas: cultura, antropologia, religiosidade, Igreja Católica e religião. É autora, entre outros, de Da doença à desordem: a cura mágica na umbanda (1985), E o verbo se faz imagem: Igreja Católica e os meios de comunicação social (co-autoria)(1991); coordenou também os seguintes trabalhos: Entre o mito e a história.

As comemorações em torno do V Centenário do descobrimento da América (1996) e Deus na aldeia: missionários, índios e mediação cultural (2006). 


\section{NOTAS}

1 Entre outras "escolhas" possíveis para os movimentos ligados à luta pela terra estavam, além do reconhecimento étnico, o confronto direto pela invasão das fazendas, a organização do pleito em termos de reforma agrária que autoriza a apropriação de terras improdutivas ou dos dispositivos legais referentes aos "posseiros" que dá a posse aos trabalhadores que vivem em uma terra por mais de uma década. No caso de Mocambo, a escolha étnica deveu-se ao fato que, por este caminho eles poderiam assegurar a posse de um número maior de pequenas propriedades.

2 No caso dos Xocós, padre Isaías, frei Enoque e o bispo Dom José Brandão se valeram dos registros históricos e antropológicos de viajantes e observadores para demonstrar legalmente a presença indígena na região. No caso dos negros, não havia registros escritos. A Fundação Palmares, ligada ao Ministério da Cultura, enviou então o antropólogo José Maurício Arruti como perito. Segundo French, embora não houvesse dúvidas quanto ao fato de que algumas das pessoas que ali viviam eram descendentes de escravos (negros ou índios), nenhuma evidência indicava que eles eram descendentes diretos de uma comunidade de escravos fugidos (2009: 99).

3 Um dos problemas teóricos do autor é associar o desenvolvimento histórico do individualismo e dos sistemas democráticos - definidos pelo momento em que o indivíduo se liberta dos antigos pertencimento (religiosos, étnicos, tradicionais etc.) - e a exigência contemporânea de respeito e reconhecimento a todo tipo de formas de afiliação.

4 Manuela Carneiro da Cunha, por exemplo, citando Marshall Sahlins, observa que "enquanto a antropologia contemporânea vem procurando se desfazer da noção de cultura, por politicamente incorreta (e deixá-la aos cuidados dos estudos culturais), vários povos estão mais do que nunca celebrando a sua 'cultura' e utilizando-a com sucesso para obter reparações por danos políticos". Para dar conta desse fenômeno a autora propõe distinguir a categoria cultura da categoria "cultura" (com aspas) (2009: 313).

5 Ver, por exemplo, para a questão indígena, Darcy Ribeiro (1979), Roberto Cardoso de Oliveira (1972, 1976), Júlio César 
Melatti (1972) e para a questão afro-brasileira, Gilberto Freyre (1992), Roger Bastide (1971), Sérgio Buarque de Holanda (1973), Renato Ortiz (1985), entre muitos outros.

6 Desde a República os intelectuais se ocuparam com o problema da construção da nação brasileira. Todos os grandes intérpretes do Brasil até os anos 1930 - Caio Prado, Paulo Prado, Eduardo Prado, Gilberto Freyre etc. - buscavam um modo de traduzir a variedade racial em alguma forma de homogeneidade nacional.

7 O Código Civil brasileiro promulgado em 1916 estabelece que as populações indígenas não podem exercer direitos individuais porque são "relativamente incapazes" e, portanto, deveriam ser tutelados por um órgão indigenista da União até que estivessem integrados à nação. A Constituição de 1988 não fala mais em tutela, mas o "Estatuto do Índio" de 1973 ainda não foi adequado aos termos da nova Carta.

8 A história da formação do Brasil como nação se confunde em grande parte com a história da ocupação de seu território. A formação do latifúndio e suas transformações é uma chave de leitura importante da construção da nacionalidade. A concentração da propriedade fundiária iniciou-se no Período Colonial e se consolida nos séculos XIX e XX. Segundo Rocha (2005: 11), com a República, a parte da população não absorvida como mão de obra nas grandes propriedades "vai constituir um tipo de campesinato marginal em terras mais afastadas do litoral, funcionando como ponta de lança da sociedade nacional e mesmo do capital em direção ao interior, em um movimento de frentes de expansão". A ocupação desordenada do espaço territorial e a falta de atrativos econômicos de vastas regiões explicam a diversidade das formas de ocupação fundiária do país: índios, babaçuareiros, camponeses, pescadores, pantaneiros etc., têm, cada um deles, uma forma particular de se relacionar com o espaço territorial.

9 O estudo de Caroline Cotta de Mello Freitas-Hupsel (2010) sobre o atual nacionalismo Aymará mostra como as condições históricas da formação do Estado nacional boliviano levaram a outra forma de lidar com a etnicização dos conflitos e das demandas políticas. Embora exista um amplo consenso na manutenção do aparato do Estado nacio- 
nal, as populações indígenas, lideradas pelo discurso katarista, reivindicam a reconstituição dos territórios originários e as formas originárias de poder político e de justiça organizadas em chefaturas locais rotativas fundadas em relações de parentesco.

10 Esse direito coletivo ao território impede os índios de alienar a terceiros seu usufruto ou a venda da posse da terra a terceiros. Também restringe a exploração comercial dos recursos ambientais.

11 Segundo Manuela Carneiro da Cunha (2009) quando a palavra "reserva" foi usada pela primeira vez em 1985 pelo seringueiro, líder sindical Chico Mendes, ela não tinha um significado preciso. Enfatizava apenas que aquelas terras deveriam ter o mesmo tipo de proteção que as terras indígenas.

12 Sérgio Costa (1997: 182-183) identifica dois modelos principais de Esfera Pública na literatura internacional: o modelo pluralista que pensa a Esfera Pública à imagem de um mercado no qual os diferentes interesses organizados se encontram em permanente concorrência pelo monopólio de um bem relativamente escasso: a visibilidade pública; o modelo discursivo de Jürgen Habermas que não vê a Esfera Pública como mero palco de luta entre atores organizados, mas como instância mediadora entre os fluxos comunicativos gerados nas práticas cotidianas e os colegiados competentes que articulam institucionalmente o processo de formação da vontade coletiva. 


\section{REFERÊNCIAS BIBLIOGRÁFICAS}

Arruda, Rinaldo. Territórios indígenas no Brasil: aspectos jurídicos e socioculturais. In: Salomon, Marlon; Silva, Joana A. Fernandes \& Rocha, Leandro (orgs.). Processos de territorialização. Entre a história e a antropologia. Goiânia: Universidade Católica de Goiânia, 2005, p. 81-104.

Arruti, José Maurício. Mocambo. Antropologia e história do processo de formação quilombola. São Paulo: Anpocs, 2005. Bastide, Roger. As religiões africanas no Brasil. São Paulo: Edusp, 1971.

Costa, Sérgio. Dois Atlânticos. Teoria social, anti-racismo, cosmopolitismo. Belo Horizonte: Ed. UFMG, 2006.

. Diferença e identidade: a crítica pós-estruturalista ao multiculturalismo. In: Vieira, Liszt (org.). Identidade e globalização: impasses e perspectivas da identidade e a diversidade cultural. São Paulo: Record, 2009, p.33-60.

Contextos da construção da esfera pública no Brasil. Novos Estudos Cebrap, 1997, 47, março, p. 179-192.

Cunha, Manuela Carneiro da. Cultura com aspas e outros ensaios. São Paulo: Cosac Naify, 2009.

Freyre, Gilberto. Casa grande \& senzala. $30^{\mathrm{a}}$ ed. Rio de Janeiro: Record, 1992.

Freitas, Caroline Cotta de M. Estado plurinacional e autonomias: a construção de um novo pacto nacional na Bolívia? Exame de qualificação (Doutorando em Antropologia Social), Universidade de São Paulo, 2010, mimeo.

French, Jan Hoffman. Legalizing identities. Becoming Black or Indian in Brazil's Northeast. Chapel Hill: The University of North Carolina Press, 2009.

Geertz, Clifford. Anti anti-relativismo. In: . Nova luz sobre a Antropologia. Rio de Janeiro: Jorge Zahar, 2000, p. 47-68. Holanda, Sérgio Buarque de. Raízes do Brasil. Rio de Janeiro: José Olympio,1973.

ISA - Instituto Socioambiental. Povos indígenas no Brasil. São Paulo: Câmara Brasileira do Livro, 2000.

Kymlicka, Will. Politics in the vernacular: nationalism, multiculturalism, citizenship. Oxford: Oxford University Press, 2001. 
Melatti, Julio César. Messianismo Kraó. São Paulo: Edusp,1972. Montero, Paula (org.) Deus na aldeia. São Paulo: Ed. Globo, 2006.

; Arruti, José Maurício \& Pompa, Cristina. Antropologia do político. In: Lavalle, Adrian G. (org.). El horizonte de la política. Mexico: Ciesas, 2011, p.169-206.

Nobre, Marcos. Desenvolvimento sustentável: a institucionalização de um conceito. Brasília: Ed. Ibama, 2002.

Oliveira, Roberto Cardoso de. O índio no mundo dos brancos. São Paulo: Pioneira, 1972.

___-_. Identidade, etnia, estrutura social. São Paulo: Pioneira, 1976.

Ortiz, Renato. Cultura brasileira e identidade nacional. São Paulo: Brasiliense, 1985.

Ribeiro, Darcy. Os índios e a civilização. A integração das populações indígenas no Brasil moderno. Petrópolis: Vozes, 1979.

Sartori, Giovanni. La sociedad multiétnica. Pluralismo, multiculturalismo y extranjeros. Mexico: Taurus, 2001.

Taylor, Charles. The politics of recognition. In: Gutmann, Amy (ed.). Multiculturalism: examining the politics of recognition. Princeton: Princeton University Press, 1994. p. 25-74. 


\section{Palavras-chave: Resumo:}

Multiculturalismo; Pluralismo; Relativismo; Espaço público; Identidades discursivas.

Keywords:

Multiculturalism; Pluralism; Relativism; Public space; Discoursive identities.
Este artigo procura examinar os efeitos das condições contemporâneas de "encolhimento do mundo" na redefinição do lugar das diferenças nas sociedades pós-nacionais. A coexistência de práticas culturais discrepantes em um mesmo marco legal passou a exigir novas modalidades de gerenciamento e de partilha do espaço político. Com o declínio do relativismo cultural como doutrina política persuasiva, e o avanço das reivindicações multiculturais, intelectuais, juristas e governantes se colocaram o problema teórico e político da redefinição do lugar das diferenças no interior das nações. Propomo-nos neste ensaio contribuir para o avanço da reflexão sobre os novos modelos de gerenciamento e partilha do espaço político desenvolvendo dois principais argumentos: a) as identidades são construídas discursivamente e dependem de um trabalho de mediação cultural; b) as configurações das demandas multiculturais dependem das particularidades históricas de formação dos Estados nacionais e de sua contrapartida, as configurações particulares do espaço público.

\footnotetext{
Abstract:

This article seeks to examine how the new global contemporary conditions lead to the redefinition of differences in post-national societies. The coexistence of disparate cultural practices in a single legal framework requires new ways of managing and sharing political space. With the decline of cultural relativism as a persuasive political doctrine, and the advancement of multicultural claims, intellectuals, lawyers and Government officials had the political and theoretical problem of resetting the place of differences within Nations. We propose in this essay to examine the new models of political management and sharing of space developing two main arguments: a) identities are discoursively constructed, and they depend consequently on a cultural mediation work; b) multicultural demands depend on the historical peculiarities of formation of national States and its counterpart, the particular settings of public space.
} 